\title{
¿DE QUÉ HABLAMOS CUANDO HABLAMOS DE AMOR?'1 \\ UN ANÁLISIS A LAS METÁFORAS DEL AMOR EN ALGUNAS CANCIONES DE POP ROCK EN ESPAÑOL
}

\author{
Sonia Liced Sánchez Rivera \\ Corporación Universitaria Minuto de Dios - Uniminuto (Colombia) \\ profsoniasanchez@yahoo.es
}

Recibido: 29/11/2019 - Aprobado: 09/03/2020

DOI: doi.org/10.17533/udea.lyl.n77a05

\begin{abstract}
Resumen: Se presentará el análisis de las metáforas del amor en algunas canciones de pop rock en español, según los postulados de Lakoff y Johnson (1987). El trabajo surgió de la conceptualización y aplicación de la metáfora en la música. Se partió de la concepción de las metáforas dentro del plano cognitivo. A partir del estudio de 40 canciones, se concluyó que las metáforas del amor pueden tener dos sentidos: por un lado, asocian al amor con otros dominios ambivalentes; por otro lado, evidencian su valoración al concebirlo como una construcción social, cultural e ideológica.
\end{abstract}

Palabras clave: metáfora; amor; lenguaje; pop rock en español; música; discurso.

\section{WHAT WE TALK ABOUT WHEN WE TALK ABOUT LOVE? AN ANALYSIS OF LOVE METAPHORS IN SOME POP ROCK SONGS IN SPANISH}

\begin{abstract}
The analysis of love metaphors will be presented in some pop rock songs in Spanish, according to the postulates of Lakoff and Johnson (1987). The work arose from the conceptualization and application of metaphors in music. It was started from the conception of metaphors within the cognitive plane. From the study of 40 songs, it was concluded that love metaphors may have two meanings: on the one hand, they associate love with other ambivalent domains; on the other hand, they show their appreciation, by conceiving it as a social, cultural, and ideological construction.
\end{abstract}

Key words: metaphor; love; language; pop rock in Spanish; music; discourse.

1. Artículo de investigación presentado como ponencia en el III Congreso Internacional de Investigación Lingüística, realizado en la Universidad de Antioquia entre el 4 y el 6 de septiembre de 2019. 


\section{A manera de introducción}

$\mathrm{E}$ 1 amor como concepto encuentra en el lenguaje un mecanismo de proyección. Cuando se habla o se escribe sobre el amor, suele representarse de diversas formas. Muchas de estas representaciones encarnan metáforas que cumplen la función de convertir una noción abstracta en algo concreto. Lakoff y Johnson (1987) señalaron que la metáfora es un recurso de la mente que opera en la representación del mundo, haciendo posible exteriorizar ideas y sensaciones en correspondencia con la manera en que se experimentan. La metáfora sirve entonces para «extrapolar dichas sensaciones e ideas» (Bogarín, 2014, p. 311), en coherencia con el proceso de construcción mental. En este sentido, la metáfora pone en evidencia la forma cómo algo ha sido conceptualizado y cómo esa comprensión ha implicado la integración de un concepto análogo, según Lakoff y Johnson porque «la esencia de la metáfora es entender y experimentar una cosa en términos de otra» (Lakoff \& Johnshon, 1987, p. 41). En la misma línea, Turner (1991) mencionó que esta es un esquema que posibilita intercambios semánticos, los cuales dan cuenta de los atajos de la mente para organizar, proyectar y narrar el mundo.

Las metáforas, como parte del funcionamiento de los discursos, hacen circular imaginarios, creencias y opiniones que afectan la manera en que se percibe, se interpreta y se experimenta la realidad. Y el amor, como tópico discursivo, no es la excepción. Tanto en las interacciones cotidianas como en la prensa, las redes sociales, la televisión o el cine se habla del amor. La música no ha sido ajena a ese intento de materializarlo y entenderlo. Desde los boleros hasta el reggaetón, pasando por la salsa y el pop, las palabras de las canciones han servido para plasmar ese universo de sensaciones, emociones e ideas que integran la experiencia del amor.

En consideración a lo anterior, este trabajo se propuso identificar y analizar diferentes metáforas sobre el amor en canciones de pop rock en español, difundidas entre los años 80, 90 y 2000, a razón de las discusiones sobre los discursos del amor y las estrategias discursivas que intervienen en su construcción. ${ }^{2}$ De la observación de este fenómeno surgió la cuestión de indagar sobre los recursos que ofrece el lenguaje para representar, expresar y construir realidades, así como la de analizar los procesos de significación propiciados por los discursos.

2. Trabajo adelantado por el Semillero de Investigación Discurso y Comunicación, adscrito al programa de Licenciatura en Humanidades y Lengua Castellana, en la Corporación Universitaria Minuto de Dios, sede Bogotá. 
Así pues, este ejercicio respondió a dos planteamientos. El primero se centró en el análisis del discurso como campo de estudio y aplicación de múltiples categorías y conceptos derivados de las teorías del lenguaje, que se propone desvelar el significado de los discursos (Otaola, 1989). En esta perspectiva se identifica a la música ${ }^{3}$, en tanto discurso (Agawu, 2012), partiendo del hecho de que esta es un entramado de elementos estructurales, perceptivos, sociales, culturales e ideológicos. En las letras de las canciones, como en cualquier discurso, se articulan formas y contenidos que significan en función del contexto. De esta manera, la música plantea un problema de significado que empuja a los analistas a pensar qué quieren decir las canciones. Este problema supone de entrada entender que los significados expresados en estos discursos no son unívocos y que dependen de saberes contextuales o que movilizan información diferente a la lingüística.

El segundo planteamiento se enfocó en el amor como un hecho social y discursivo, es decir, una emoción que se construye cotidianamente en la interacción mediada por el lenguaje. Harré (1984) manifestó que las emociones son construcciones sociales, fruto de la interacción de factores culturales, sociales y cognitivos, que se exploran y expresan en formas discursivas. El amor, entendido bajo la égida de las emociones, constituye uno de los grandes temas de la humanidad, cuyas representaciones se filtran en el léxico y las expresiones.

Los vínculos entre emoción y lenguaje fueron develados en la obra de Oatley (2007), en la cual se advirtió que:

[...] en 500 años de historia de la escritura las emociones han sido los argumentos más interesantes. Sobre todo existe una emoción que es la que más se ha utilizado en 500 años de historia de la escritura que es el amor (Oatley, 2007, citado por Belli 2009, p. 23).

Belli (2009) afirmó que, en casos como el de la literatura, las palabras buscan transmitir la emoción de amor de una persona a otra, intentando introducir las emociones a las palabras, e inversamente hablando, la emoción de amor es construida a través de unidades lingüísticas. De ahí que se plantee que el discurso construye y reconstruye el amor, le crea un contexto y le transfiere unas acciones y unos valores.

Estos puntos de vista, que se enfatizaron en el estudio de las emociones como producciones sociales y lingüísticas, sustentan el interés en desentrañar los vínculos entre las emociones, el pensamiento y el lenguaje, en cuya intersección se encuentra la metáfora.

3. Dada la amplitud de este concepto, en este trabajo se abordaron solo las unidades lingüísticas representadas en las letras de las canciones, que corresponden a una parte del lenguaje musical, sin profundizar en cuestiones propias de la musicología. 
Empleada para hablar del amor y cristalizar las diferentes maneras de entenderlo, en discursos que van desde la poesía hasta la música, pasando por la ciencia y la religión, la metáfora conceptual surca los límites de la interpretación meramente lingüística y llega a impregnar las estructuras conceptuales que posibilitan la percepción y la comprensión de la realidad. Por lo tanto, el análisis metafórico contribuye al estudio de las representaciones sobre el mundo que tejen los seres humanos. Dichas concepciones, que suelen ser concordantes con unas visiones del mundo, reflejan relaciones y significados incrustados en el horizonte de una cultura. Así, el estudio de las metáforas y expresiones metafóricas del amor permite «reconstruir las estructuras y significaciones simbólicas que los sujetos despliegan en la mente» (Suárez, 2006, p. 49) para materializar y socializar dicha emoción.

De este modo, la exposición del presente estudio continuará de la siguiente manera: en el próximo apartado, se presentarán los principios teóricos que guiaron el análisis; enseguida, se realizará la exposición del método y la justificación del corpus: luego, se propondrá el análisis de metáforas y expresiones metafóricas; y, finalmente, se señalarán algunas conclusiones al respecto.

\section{Elementos teóricos del estudio}

Para describir y analizar las metáforas del amor en el discurso de la música, se recurrió a una teoría que ha flexibilizado el carácter literario de las metáforas y de las metonimias, llevándolas al nivel del lenguaje cotidiano, sin por ello restarles valor o capacidad para representar de manera poética el mundo. Esta teoría tiene sus raíces en los planteamientos de Lakoff y Jonhson (1987), los cuales han sido enriquecidos por otros trabajos (Gibbs, 1994; Kövecses, 2010; Soriano, 2012; Gibbs \& Raymond, 2017; Steem, 2017). Estos estudios apoyaron el análisis conceptual de las metáforas e hicieron hincapié en su papel de configurar significados que influyen en la descripción de los sujetos, objetos, procesos y fenómenos constitutivos de la experiencia en la realidad.

La teoría en cuestión ubica la metáfora en el dominio de lo cognitivo, explicando su funcionamiento en los procesos de pensamiento. En palabras de Lakoff y Jonhson: «La metáfora impregna la vida cotidiana, no solamente el lenguaje, sino también el pensamiento y la acción. Nuestro sistema conceptual ordinario, en términos del cual pensamos y actuamos, es fundamentalmente de naturaleza metafórica» (Lakoff \& Johnson, 1987, p. 39). Desde esta 
perspectiva, la metáfora es un mecanismo conceptual de comprensión y expresión de aquello que resulta ininteligible.

Las metáforas permiten estructurar conceptos a partir de su correlación con otros conceptos. Se parte de campos conceptuales concretos para estructurar otros que suelen ser más abstractos. Por ejemplo, en las metáforas orientacionales, descritas por Lakoff y Johnson (1987) como aquellas que dan a un concepto una orientación espacial basándose en la experiencia física y la cultura, se toma la relación de orientación espacial como referencia. Así, al revisar el significado de expresiones como tener la moral en el piso, estar bajo de nota o no levantar cabeza, usadas en español para aludir a un estado de tristeza o desánimo, se puede establecer que los estados de ánimo son representados a través de un plano vertical, orientado de arriba abajo, en el cual la tristeza se asocia a estar abajo y la felicidad a estar arriba. Esta noción de verticalidad usada en el lenguaje cotidiano impregna muchas otras expresiones, tales son el caso de estar en las nubes o estar en la luna, para decir que alguien está distraído o no presta atención. En todas estas expresiones se construye una relación entre dos entidades o dominios conceptuales, una suerte de asociación implícita que contribuye a la comunicación del pensamiento.

Evidentemente, la metáfora juega un papel esencial en el sistema conceptual, pues en este se convierte en un instrumento para «comprender y expresar situaciones complejas sirviéndose de conceptos más básicos y conocidos» (Lakoff \& Johnson, 1987, p. 39). Para explicar mejor esta propiedad, los autores se remitieron al sistema interno que da forma a una metáfora. En sus términos, esta se elabora por la correspondencia entre dos dominios: uno de origen y otro de destino. El primero es el dominio del que se parte y el segundo al que se llega, y en esta lógica el primero proyecta sus conceptos sobre el segundo. Así: «La metáfora se entiende como la proyección de unos conceptos desde un dominio conceptual (el dominio origen) hacia otro dominio conceptual (el dominio destino)» (Cuenca \& Hilferty, 2007, p. 101).

Un ejemplo de ello, referenciado por Cuenca y Hilferty (2007), desarrollado luego por Soriano (2012), se encuentra en expresiones como invertir bien el tiempo, ganar algo de tiempo o perder tiempo, en las cuales se asocia el tiempo con un objeto, en este caso el dinero. De esta forma, el tiempo y sus relaciones se representan mediante un concepto más claro y próximo a la experiencia física, advirtiendo la correlación entre el tiempo y el dinero como entidades medibles, difíciles de gestionar y altamente valoradas en la sociedad. 
Esto último permite a su vez explicar las proyecciones entre los dominios origen y destino. Para esto, Lakoff y Johnson (1987) emplearon las correspondencias ontológicas y correspondencias epistémicas. Las primeras identifican la existencia de elementos análogos que permitan establecer la comparación, mientras que las segundas expresan el conocimiento común entre ambos dominios. En el ejemplo en cuestión, las primeras conciernen al hecho de que las personas disponen de dinero al igual que de tiempo, mientras que las segundas, al hecho de saber que tanto el dinero como el tiempo representan un valor.

Paralelamente, el tiempo es dinero constituye lo que los autores han denominado una «metáfora conceptual», la cual es un esquema mental y abstracto que se materializa lingüísticamente en expresiones metafóricas. En otras palabras, las metáforas conceptuales son las ideas de las que se derivan expresiones metafóricas, es decir, ahorrar tiempo, no malgastar el tiempo o tener más o menos tiempo serían expresiones metafóricas de la idea metafórica el tiempo es dinero. La distinción entre estas dos categorías resulta esencial para el análisis a desarrollar más adelante, en tanto, tal como sucede con el tiempo, el amor ha sido también conceptualizado a través de ideas y de bloques cognitivos que agrupan expresiones en las que se cristalizan concepciones del amor.

A este respecto, el trabajo de Kövecses (1998) sobre las metáforas del amor estableció la existencia de correspondencias entre las sensaciones y emociones ligadas a la experiencia del amor con metáforas propias de cada cultura y por tanto de cada lengua. Otros estudios, como el de García-Olivares (2007) sobre el amor en el tango, resultaron reveladores en cuanto muestran la variedad de conceptualizaciones, ligadas tanto a la subordinación como a la emancipación, a la pasión como a la ternura, a la lucha como a la cooperación, señalando además el binarismo al que ha sido constantemente sometido este concepto. En este estudio se resaltó también la forma cómo este género estructura una serie de metáforas que despliegan saberes y experiencias basadas en categorías como los riesgos del amor, los estragos del amor, los espejismos del amor, los efectos del desamor o las diferentes maneras de amar.

En síntesis, evocando los postulados de Gibbs (2008), el concepto de metáfora contribuye a la exploración del lenguaje, del pensamiento y de la cultura; así mismo, es un instrumento de análisis del proceso de comprensión y producción del lenguaje figurado, de la poética interna que impregna el entendimiento de los conceptos y de las emociones. En esta línea, Radman (1997) afirmó que las metáforas reconfiguran las propias ideas, permiten una interacción entre el mundo interior abstracto y el mundo exterior físico, y además «explica los 
hechos sociales, rotula los diferentes momentos históricos y abre nuevas perspectivas de conocimiento» (Radman, 1997, p. 117).

\section{Corpus y método de la investigación}

El interés por la música se justifica en tanto que es una producción cultura, la cual concierne a todas las personas. Tomada como un discurso, ella tiene la capacidad de transmitir sentimientos e ideas, de interpelar opiniones y posicionamientos, lanzando significados que provocan efectos en la forma de pensar y actuar. De manera específica, se eligió el pop rock en español, por ser un género que comunica modos de vida y concepciones del mundo que se insertan en el universo simbólico de una generación, que continúa vigente a través de las generaciones de jóvenes que en la actualidad escuchan e interiorizan muchas de sus canciones. Así, en palabras de Castillo (2011): «el rock/pop es el sonido joven por excelencia, englobando a múltiples estilos musicales destinados al público juvenil en una primera época y después a un público más general, desde el auge del rock and roll hasta nuestros días». De otro lado, se decidió elegir las composiciones que surgieron entre los años 80 y 90, ya que en estas dos décadas se dio el momento de mayor esplendor del género, el cual le dio su identidad y reconocimiento entre el público. Adicionalmente, una lectura $a$ priori de las letras de las canciones reveló que el amor es una de sus temáticas más recurrentes, apreciación que se puede sustentar, en alguna medida, en el estudio realizado por Martínez Casas (2016), en el cual se analizó el corpus de pop rock español (CEPRE) y se encontró que el amor es el sustantivo que registra mayor frecuencia.

En concreto, para el presente estudio se analizaron 40 canciones de solistas y bandas (Andrés Calamaro, Joaquín Sabina, Charly García, Jorge Drexler, Luis Alberto Spinetta, Los Prisioneros, Soda Stereo, Aterciopelados, El Último de la Fila, Café Tacvba, Miguel Mateos, Attaque 77, Los Rodríguez, Los Auténticos Decadentes, Serú Girán, Estopa, Amaral, Fito Páez, Enrique Bunbury y Miguel Bosé) de algunos países de habla hispana (España, México, Colombia, Argentina, Uruguay y Chile), surgidas entre las décadas de los 80, 90 y 2000, cuyas letras hacen referencia al amor. El estudio, de base cualitativa, se focalizó en revelar tanto las metáforas conceptuales como las expresiones metafóricas sobre el amor presentes en el corpus, lo cual podría dar luces sobre la manera como se sincronizan las estructuras 
mentales y las unidades lingüísticas en el momento de conceptualizar el amor en las canciones de pop rock en particular y en otros géneros musicales.

\section{Resultados y discusión. Hablar del amor/Pensar el amor}

El título de este artículo toma prestado el nombre de la famosa novela del escritor estadounidense Raymond Carver ¿De qué hablamos cuando hablamos de amor? (1981); en ella el autor esboza, a lo largo de diecisiete relatos, diversas ideas sobre el amor que nace y se desarrolla en una relación de pareja. En su libro, Carver narró diferentes experiencias del amor, en las cuales se lo relaciona con estados y sentimientos contrarios: el odio, la muerte, la infidelidad, la traición, la admiración, la vida, la compasión y la lealtad.

A la manera de Hiernaux (2009), los significados opuestos integrados a la representación de ciertos fenómenos son resultado de una tendencia a construir las realidades desde las dicotomías. El binarismo se convierte en un sustento importante de las formas de entender el amor, el cual ha embebido la semántica de este concepto y su evolución social, histórica y cultural.

A continuación, se describirán y examinarán diversas metáforas del amor identificadas en el análisis del corpus ${ }^{4}$ :

-El amor es una guerra: Una de las metáforas conceptuales más empleadas deriva de la percepción del amor como conflicto, explorada en los trabajos de Lakoff y Johnson (1987). Dicha metáfora parte del dominio de la guerra y se proyecta al dominio del amor basándose en correspondencias ontológicas y epistémicas. Las primeras establecen que en el amor como en la guerra existe un conflicto en el que los participantes son adversarios. Las segundas sugieren que, a semejanza de un cuadro bélico, se aplican estrategias de violencia, donde se llevan a cabo batallas y se presentan heridos y bajas. Esta correlación de dominios irradia a su vez las expresiones metafóricas en las que se observan palabras que conducen al dominio origen (la guerra) y al dominio destino (el amor). En términos semánticos, vocablos como soldado, batalla y derrota funcionan como colocaciones vinculadas al campo semántico de la guerra que se proyectan al campo del amor, mostrando, a los miembros de la pareja como rivales (jefe o subalterno, débil o fuerte), a las discusiones como batallas y al final de la

4. La lista detallada de canciones, autores y fecha de lanzamiento se encuentra al final de este documento a modo de anexo. 
relación como una derrota. Del mismo modo, estas expresiones metafóricas invocan ciertas acciones (atacar, defenderse, morir, matar, herir o conquistar), las cuales suelen emplearse en el lenguaje cotidiano para hablar del amor. Estas acciones describen formas de entenderlo, las cuales son difundidas y legitimadas en una cultura. Se habla del amor en términos de guerra porque así se percibe o porque así se ha experimentado. Al respecto, Lakoff y Jonhson (1987) concluyeron: «consideramos algunos de los valores culturales de nuestra sociedad que son coherentes con nuestras metáforas» (Lakoff \& Johnson, 1987, p. 59).

\begin{tabular}{|c|c|}
\hline Metáfora conceptual & Expresiones metafóricas \\
\hline El amor es una guerra & $\begin{array}{l}\text {-No estás completamente inventada, te falta algo, te falta } \\
\text { amor, te falta ser como son los soldados que mueren junto al } \\
\text { frente amor. García, C. (1994). Faux U. } \\
\text {-Anda, pídeme que viole las leyes que te encarnan, que no } \\
\text { quede intacto ni un poro en la batalla. Drexler, J. (2004) } \\
\text { Anda. } \\
\text {-Yo soy tu soldado de lata, que lucha y que mata por vos. } \\
\text { García, C. (1998). Soldado de lata. } \\
\text {-La última guerra fue con mando a distancia, el dormitorio } \\
\text { era un vagón de soldados. Páez, F. y Sabina J. (1998). Llueve } \\
\text { sobre mojado. } \\
\text {-No se fíe de una baby pelirroja, peligrosa, estratega a la } \\
\text { sombra, dura como la roca puede cantar derrota que no se } \\
\text { deja querer. Bunbury, E. (2002). No se fíe. } \\
\text {-No hay un corazón que valga la pena, ni uno solo que no } \\
\text { venga herido de guerra. Bosé, Miguel. (2002). No hay } \\
\text { corazón que valga la pena. } \\
\text {-¿Cuántas cosas se dirán? en la guerra del amor las palabras } \\
\text { son cuchillas cuando las manejan orgullos y pasiones. Los } \\
\text { Prisioneros. (1990). Estrechez de corazón. }\end{array}$ \\
\hline
\end{tabular}

Tabla 1. El amor es una guerra. Metáfora conceptual y expresiones metafóricas

Desde luego, esta conceptualización tiene implicaciones en la práctica misma del amor en cuanto vincula la noción de poder inherente al destino de una relación de pareja, en la que alguien determinadamente gana o pierde. A la luz de esta metáfora, la guerra como el amor 
son escenarios donde se miden fuerzas, se ejerce poder de uno sobre el otro y los roles encarnan una estructura jerárquica.

-El amor mata/salva: Tal como ya se ha señalado, en las canciones analizadas se encontró también una tendencia a representar el amor en términos binarios: negativos, asociados a estados como la enfermedad, el dolor y la soledad; y positivos, relacionados con la felicidad, la vida, la protección y la esperanza. Esa dualidad simboliza la tensión de las fuerzas del amor que fluctúan entre el bienestar y el padecimiento, dos formas de imaginarlo que han existido desde siempre en la cultura. Estas metáforas muestran que el sistema lingüístico entiende y expresa las cosas metafóricamente, reflejando estados mentales o emocionales y los efectos provocados en el ser humano. De ahí que se construyan metáforas conceptuales que ligan esos estados a reacciones físicas.

En este sentido, se cree que las decepciones, los engaños o el amor no correspondido conllevan a sufrir lesiones, heridas o fracturas, e incluso la muerte. Simultáneamente, se toma a quien está enamorado como a un enfermo y al amor de la persona amada como una pócima o droga que alivia. De esta manera, la metáfora indica que el amor debilita, genera dolor e inestabilidad, instaurando la idea de que este comporta una dosis de sufrimiento. En contrapunto, aparecen metáforas que vinculan el amor a estados y valores más benévolos; según estas, el ser amado es una especie de salvador o protector, de modo que el amor se piensa como un proveedor de luz, de claridad y de energía. A diferencia de las metáforas conceptuales que asocian el amor al campo de la enfermedad y la muerte, estas lo enlazan a la vida y a la dicha, enfatizando más en la realidad espiritual que en la física.

\begin{tabular}{|l|l|}
\hline \multicolumn{1}{|c|}{ Metáfora conceptual } & \multicolumn{1}{c|}{ Expresiones metafóricas } \\
\hline \multirow{5}{*}{} & $\begin{array}{l}\text {-Soy el remedio sin receta y tu amor mi enfermedad. Los } \\
\text { Rodríguez (1991). Mi enfermedad. } \\
\text {-Me arde, es tarde para curarme, me arde, me quema, dejé la } \\
\text { sangre en la arena. Calamaro, A. (1997). Me arde. } \\
\text { El } \\
\text {-No quiero más que me des con cuentagotas tu amor. García, } \\
\text { C. (2003). Asesíname. } \\
\text { amor es } \\
\text {-Quiero desintoxicarme, cortar esta dependencia antes que } \\
\text { sea tarde. Aterciopelados. (1998). Maligno. } \\
\text {-Eres el hacha que astilló toda mi vida. Aterciopelados. } \\
\text { (1998). Maligno. }\end{array}$ \\
\hline
\end{tabular}




\begin{tabular}{|c|c|}
\hline enfermedad/duele/mata & $\begin{array}{l}\text {-Afiladas fueron tus miradas, quedé destrozada y en llanto } \\
\text { inundada. Aterciopelados. (1998). Rompecabezas. } \\
\text {-No me lastimes, por qué conmigo, habiendo tantos } \\
\text { corazones heridos. Mateos, M. (1986). Romper un corazón. } \\
\text {-Quiero intoxicarme en vos, arrancacorazones, dame tu } \\
\text { droga. Ataque } 77 \text { (2003). Arrancacorazones. } \\
\text {-Lo que yo quiero, corazón cobarde, es que mueras por mí. } \\
\text { Sabina, J. (1996). Contigo. } \\
\text {-Se aferra el corazón a lo perdido, los ojos que no ven miran } \\
\text { mejor, cantar es disparar contra el olvido, vivir sin ti es morir } \\
\text { en la estación. Los Rodríguez y Sabina, J. (1995). Todavía } \\
\text { una canción de amor. }\end{array}$ \\
\hline $\begin{array}{l}\text { El amor es } \\
\text { cura/alivia/salva }\end{array}$ & $\begin{array}{l}\text {-Quiso una estrella iluminar mi camino cuando más ciego } \\
\text { estuve. Bunbury, E. (2004). El rescate. } \\
\text {-Vivo despertando desde que te encontré. Calamaro, A. } \\
\text { (2006). Miami. } \\
\text {-Tu amor, parábola de un mundo mejor. García, C. y Aznar, } \\
\text { P. (1991). Tu amor. } \\
\text {-Te pido que me cures esta herida. Yo sé muy bien que no es } \\
\text { tu obligación. Tan solo si amortiguas mi caída será mi } \\
\text { salvación. Café Tacvba. (2007). Quiero ver. } \\
\text {-Sos mi escudo ante el miedo, y aunque se derrumbe el cielo, } \\
\text { nunca vas a estar solo, porque siempre estaré. Los Auténticos } \\
\text { decadentes y Venegas, J. (2003). A mí no me importa el } \\
\text { dinero. } \\
\text { - Eres. El tiempo que comparto, eso eres, lo que la gente } \\
\text { promete cuando se quiere. Mi salvación, mi esperanza y mi } \\
\text { fe. Café Tacvba. (2003). Eres. }\end{array}$ \\
\hline
\end{tabular}

Tabla 2. El amor mata El amor salva. Metáfora conceptual y expresiones metafóricas

En concordancia, este tipo de ideas sobre el amor surge de la relación de los individuos con su cuerpo, en tanto eje de la percepción del mundo. En los casos anteriores, pensar y decir que el amor enferma o intoxica es extrapolar al dominio del cuerpo, de la manera más exacta, aquello que se siente. De acuerdo con Gibbs (2006) se trata de metáforas «corporeizadas», 
que trasladan nociones o conceptos de un dominio concreto a otro abstracto. Así, el concepto abstracto del amor se emparenta a otros palpables sensorialmente, como la claridad o el despertar, lo que significa que, si el amor reconforta, lleva a la persona a sentirse bien y a conducirse mejor.

En torno a las metáforas mencionadas, habría que preguntarse por qué en los esquemas mentales, como ya se dijo, funcionan adaptándose a valores culturales, existe una propensión a considerar que tener amor significa estar a salvo, y no tenerlo indica peligro. Resulta también interesante cuestionarse sobre la adopción de palabras como salvación, parábola y fe, provenientes del campo de la religión y frecuentes en el horizonte semántico de las canciones.

—El amor es...: Dentro de la multiplicidad de metáforas del amor, existen también aquellas que recogen referencias de otras metáforas conceptuales, de sus dominios o elementos léxicos, muchas de las cuales han sido identificadas en los trabajos de Kövecses (2000). En esta «red de metáforas» el amor es representado como un territorio de disputa, como un elemento que aporta o sustrae energía o como un perturbador de la libertad o la razón. Así, la metáfora conceptual el amor es un juego se cimienta sobre la idea del amor como un enfrentamiento, una competición en la que alguien vence a otro, en la misma línea conceptual de la metáfora el amor es una guerra. Igualmente, en la conceptualización de la metáfora el amor es una cárcel se sitúan correspondencias ontológicas y epistémicas que hacen referencia al enamorado como a un prisionero y al amor como a un sentimiento que lo atrapa. En esta analogía, se enuncia que el amor puede interpretarse como un lugar de captura, de control y de dominación, conduciendo a quien se deja atrapar a quedarse sin libertad emocional.

Por su parte, metáforas del tipo el amor es calor, se desprenden de la metáfora conceptual el afecto es calor, revisada entre otros por Grady (1999). Desde esta perspectiva, el calor se acopla para simbolizar el afecto, y, en este caso el amor. De ahí provienen expresiones metafóricas que proponen el amor como un factor de temperatura, que llevan a asociarlo con el fuego, las llamas, el calor, el verano, o simplemente con la sensación de tibieza que provoca estar cerca o en la compañía de otro cuerpo. Esto justifica, de igual manera, que se hable de la ausencia o de la falta de amor en términos de frío, invierno o soledad. Como ya se ha visto en otros modelos metafóricos, estas correlaciones se encuentran ligadas estructuralmente a experiencias fisiológicas. 
Finalmente, el concepto metafórico el amor es locura se asocia a la falta de lucidez mental, de claridad y de juicio. Al remitir al estado mental de un enamorado, se correlaciona su conducta con el comportamiento de un demente, una analogía que propone al amor como un sentimiento que limita el entendimiento y afecta la capacidad de razonar, dejando al individuo enamorado a merced del otro que lo enajena.

\begin{tabular}{|c|c|}
\hline Metáfora conceptual & Expresiones metafóricas \\
\hline El amor es un juego & $\begin{array}{l}\text {-Amor se llama el juego, en el que un par de ciegos, juegan a } \\
\text { hacerse daño. Sabina, J. (1992). Amor se llama el juego. } \\
\text {-No me verás pidiéndote revancha. Enanitos Verdes. (1988). } \\
\text { No me verás. } \\
\text {-Es el juego del amor, cuando más parece firme un castillo se } \\
\text { derrumba de dolor. Los Prisioneros. (1990). Estrechez de } \\
\text { corazón. } \\
\text {-Algún tiempo atrás pensé en escribirle, y nunca sorteé las } \\
\text { trampas del amor. Soda Stereo. (1990). De música ligera. } \\
\text {-Estoy jugando con fuego, y en la yema de los dedos tengo el } \\
\text { tacto de los días, tengo el tacto de las noches, tengo el tacto } \\
\text { de los dos. Calmaro, A. (1999). Jugar con fuego. }\end{array}$ \\
\hline El amor es una cárcel & $\begin{array}{l}\text {-No cometas el crimen, varón. Si no, vas a cumplir la } \\
\text { condena. Calamaro, A. (1999). Paloma. } \\
\text {-Con el primer beso casi siempre voy preso. Calamaro, A. } \\
\text { (1999). Socio de la soledad. } \\
\text {-No podré vivir sin ti, lo sé, quebrado en una celda en } \\
\text { soledad. Páez, F. (1994). Nadie detiene al amor en un lugar. } \\
\text {-Aunque me hayas capturado, dejé la vergüenza a un lado. } \\
\text { Solía importarme, pero ahora mis venas arden, necesito un } \\
\text { poco más. Bunbury, E. (2002). Enganchado a ti. }\end{array}$ \\
\hline & $\begin{array}{l}\text {-Te necesito como a la luz del sol, en este invierno frío, pa' } \\
\text { darme tu calor. Amaral. (2005). Te necesito. } \\
\text {-Échale leña a la hoguera, la hoguera del sentimiento que } \\
\text { arde si estoy a tu vera. Estopa (1999). Tu calorro. } \\
\text {-No tengo nadie que me acompañe a ver la mañana, y que }\end{array}$ \\
\hline
\end{tabular}




\begin{tabular}{|c|c|}
\hline El amor es calor & $\begin{array}{l}\text { me dé la inyección a tiempo, antes que se me pudra el } \\
\text { corazón, y caliente estos huesos fríos. Serú Girán (1978). Eiti } \\
\text { Leda. } \\
\text {-A veces se enciende, a veces se apaga, la llama sagrada que } \\
\text { tú y yo conocemos. Leña que ha de arder. Vamos a } \\
\text { querernos, mi pequeño amor, como tú y yo sabemos. El } \\
\text { Último de la Fila. (1988). A veces se enciende. }\end{array}$ \\
\hline El amor es locura & $\begin{array}{l}\text {-Tus ojos, el abismo, donde muere mi razón. Amaral. (2005). } \\
\text { Te necesito. } \\
\text {-Tu perfume es el veneno que contamina el aire que tu pelo } \\
\text { corta, que me corta hasta el habla y el entendimiento, porque } \\
\text { es la droga que vuelve mi cabeza loca. Estopa (1999). Tu } \\
\text { calorro. } \\
\text {-Hoy que enloquecido vuelvo buscando tu querer. No queda } \\
\text { más que viento, no queda más que viento. Spinetta, L. A. } \\
\text { (1991). Seguir viviendo sin tu amor. }\end{array}$ \\
\hline
\end{tabular}

Tabla 3. El amor es... Otras metáforas conceptuales y expresiones metafóricas

En síntesis, este análisis pretendió mostrar las posibilidades de la aplicación de la metáfora conceptual y las expresiones metafóricas en la música como objeto discursivo. En esta medida, se relacionaron las categorías mentales en forma de dominios que intervienen en la expresión de las conceptualizaciones sobre el amor presentes en el género musical pop rock en español. Vale acotar que el lenguaje figurado presente en las letras es inherente a la concepción del amor que los intérpretes y compositores buscan transmitir en el marco de una cultura en la que pueden ser interpretados.

Así, al abordar la metáfora desde su perspectiva conceptual, en un discurso como el de la música, se amplía su configuración teórica con miras a comprender mejor su función discursiva y conceptual. Aquí resulta pertinente mencionar la idea de Newmark (1992) en la que enunció los dos posibles fines u objetivos de la metáfora:

Uno referencial, que consiste en describir un estado mental, concepto, persona, objeto, cualidad, o acción de forma más global y concisa de lo que permitiría el lenguaje literal o físico; y otro pragmático, simultáneo para estimular los sentidos, interesar, clarificar «gráficamente», agradar, deleitar, sorprender. El primero es cognitivo y el segundo estético (Newmark, 1992, p. 147).

\section{Conclusiones}


Al finalizar este estudio, se precisaron tres consideraciones importantes: la primera, concerniente al análisis del discurso como terreno interdisciplinar orientado a establecer el significado de los discursos. El estudio de la metáfora se aproximó a ese objetivo, posibilitando la interacción entre las dimensiones estructural y cognitiva del discurso (van Dijk, 2000), cuyo análisis permite entender que «el discurso crea los objetos al invocarlos de tal o cual manera y, en consecuencia, se advierte el poder que tiene el enunciador y la importancia del punto de la enunciación»(Jitrik, 1991, p. 11). En este sentido, es válido mencionar que, quizás para algunas personas, las letras de estas canciones puedan tener un efecto curativo o terapéutico, o incluso pueden ser tomadas como lecciones o consejos emitidos por alguien más experimentado en el amor. Este aspecto, vinculado a la recepción, no fue objeto de este estudio, pero puede constituir una vertiente de análisis para el futuro.

De otro lado, se encontró que muchas de estas conceptualizaciones aluden a las sensaciones corporales o estados mentales, que plantean al amor como la arena de luchas y contiendas que advierte el ejercicio asimétrico y conflictivo del amor. En general, el discurso sobre el amor ofrecido por las canciones, muestra el juego de tensiones que ha sido una constante en su definición. En esta medida, el amor puede definirse como algo sublime, sagrado o místico, pero de forma paralela, también puede encarnar el horror, la miseria y la desdicha.

La segunda conclusión está ligada a la música como discurso, la cual encuentra en la palabra un dispositivo de constitución y actualización de las significaciones, así como de los conceptos que intervienen en la organización del mundo. La música ha estado siempre en la vida de la humanidad, siendo testigo y emisaria de los asuntos más íntimos y sensibles de las personas. Por lo tanto, como producción cultural, la música sirve de referente del universo simbólico de las sociedades. Las letras de las canciones muestran una serie de relaciones que solo las producciones culturales hacen circular, en tanto en ellas permanecen fragmentos del tejido social y cultural. Frente a esta consideración, sería válido indagar posteriormente sobre la relación de estas letras con otras de géneros como el tango, el bolero o la ranchera, los cuales en su momento han develado unas concepciones del amor y del rol de sus protagonistas, que han influido en las representaciones del hombre y de la mujer (GarcíaOlivares. 2007).

La tercera conclusión, en consonancia con los postulados de Lakoff y Johnson (1987), recalca que lo dicho está más próximo a lo que se piensa, y ello es causa directa de lo que se 
hace. En otros términos, las palabras exteriorizan las ideas, y estas a su vez legitiman las acciones. Por ende, al abordar el amor empleando ciertas palabras se engendra un universo de significación en torno a esa categoría. De manera particular, este estudio permitió conocer algunas metáforas conceptuales sobre el amor que evocan sus etapas, motivaciones y efectos. Estas metáforas, materializadas en expresiones metafóricas, explotan recursos retóricocognitivos, como las metonimias y las colocaciones, lo que significa que el análisis metafórico lleva a reconocer tanto los trucos de la mente para construir una emoción como los elementos lingüísticos que los despliegan y exteriorizan.

A manera de prospectiva, este estudio es susceptible de continuarse, observando la evolución de las metáforas del amor del pop rock en español. En esta perspectiva, canciones como Puente, de Gustavo Cerati (1999), Todo se transforma, de Jorge Drexler (2004) o Bien o mal, de Julieta Venegas (2010), proponen otras visiones del amor, al concebirlo como un canal entre los seres humanos, una metamorfosis continua o una emoción única en cada individuo. De acuerdo con Judith Butler (1993), la construcción de las emociones es un proceso abierto a constantes transformaciones y redefiniciones, y el amor no escapa a ese dinamismo, por lo que merece ser revisado constantemente.

En definitiva, las reflexiones hechas ponen de manifiesto la importancia de examinar los discursos que tienen cabida en el paisaje semiótico-discursivo de la cultura contemporánea, sus significados y las ideas que movilizan, en cuanto estas sirven de sustento a las prácticas sociales y a las acciones cotidianas. En esa línea, este trabajo pretendió mostrar un análisis de la metáfora en la música como un fenómeno discursivo que integra el lenguaje y la cognición. Esta revisión desentrañó las palabras, campos semánticos y dominios conceptuales estructuradores de las metáforas que dan forma al conjunto de ideas sobre el amor, contribuyendo así a responder a la pregunta: ¿De qué hablamos cuando hablamos de amor?

\section{Referencias bibliográficas}

1. Agawu, K. (2012). La música como discurso. Aventuras semióticas en la música romántica. Buenos Aires: Eterna Cadencia.

2. Bogarín, M. (2014). Turner, Iser, poiesis metafórica y procesos de estetización. Acercamiento a la teoría y a un caso de aplicación actual. Eikasia Revista de Filosofía, 60, 301-320. 
3. Brodell, J. (2013). La música es amor y otras metáforas conceptuales por las que vivimos. La semántica y estructura gramatical de metáforas traducidas. (Tesina). Suecia: Uppsala Universitët.

4. Butler, J. (1993). Bodies that Matter: On the Discursive Limits of Sex. London: Routledge. 5. Castillo, F. (2011). La cultura rock/pop. Recuperado de http://bibliotecadigital.ucsh.cl/greenstone/collect/libros/index/assoc/HASH01a6.dir/La\%20cultura\%20rock\% 20pop.pdf

6. Carver, R. (1981). ¿De qué hablamos cuando hablamos de amor? Estados Unidos: Alfred Knopf.

7. Cuenca, M. J. \& Hilferty J. (2007). Introducción a la lingüística cognitiva. Bareclona: Ariel.

8. García-Olivares, A. (2007). Metáforas del saber popular (III): el amor en el tango. Acciones e investigaciones sociales, 23, 139-179.

9. Gibbs, R. (1994). The Poetics of Mind. New York: Basic Books.

10. Gibbs, R. (2008). The Cambridge Handbook of Metaphor and Thought. Cambridge: Cambridge University Press.

11. Gibbs, R. (2017). Metaphor Wars: Conceptual Metaphors in Human Life. New York: Cambridge University Press.

12. Grady, J. (1999). A Typology of Motivation for Conceptual Metaphor: Correlation vs. Resemblance. In Gibbs, R. \& Steen, G. (Eds.), Metaphor in Cognitive Linguistics (pp. 79100). Amsterdam: John Benjamins.

13. Groccia, M. (2015). La chanson. Essai de sémiotique théorique appliquée. Signata, 6, 121-141.

14. Harré, R. (1984). Social elements as mind. British Journal of Medical Psychology, 57(2), 127-135.

15. Hiernaux, P. (2009). El pensamiento binario. Aspectos semánticos, teórico y empíricos. Cultura y Representaciones Sociales, 3(6), 25-42.

16. Jitrik, N. (1991). El discurso del amor y no el discurso amoroso. Revista Mexicana de Ciencias Políticas y Sociales, 143(36), 11-16.

17. Kövecses, Z. (2000). Metaphor and Emotion: Language, Culture, and Body. In Human Feeling. Cambridge: Cambridge University Press. 
18. Kövecses, Z. (2010). Metaphor: A Practical Introduction. New York: Oxford University Press.

19. Lakoff, G. \& Jonhson, M. (1987). Metáforas de la vida cotidiana. Madrid: Cátedra

20. Martínez, M. (2016). El discurso del pop-rock español y su aplicación didáctica en el aula de ELE. En Cruz, O. (Ed.), La formación y competencias del profesorado de ELE: Actas del XXVI Congreso Internacional ASELE. Granada: Asociación para la Enseñanza del Español como Lengua Extranjera.

21. Newmark, P. (1992). Manual de traducción. Madrid: Cátedra.

22. Otaola, C. (1989). El análisis del discurso. Introducción teórica. Revista de Filología, 5, $81-98$

23. Radman, Z. (1997). Metaphors: Figures of the Mind. London: Kluwer Academic Publishers.

24. Soriano, C. (2012). La metáfora conceptual. En Ibarretxe-Antuñano, I. \& Valenzuela, J. (Eds.) Lingüística Cognitiva (pp. 87-109). Barcelona: Anthropos.

25. Steen, G. (2017). Deliberate Metaphor Theory: Basic Assumptions, Main Tenets, Urgent Issues. Intercultural Pragmatics, 14(1), 1-24.

26. Suárez, H. (2006). La palabra y el sentido. Análisis del discurso de Joaquín Sabina. Revista Mexicana de Sociología, 68(1), 49-79.

27. Turner, M. (1991) The Study of English in the Age of Cognitive Science. New Jersey: Princeton University Press.

28. Van Dijk, T. (2000). El discurso como estructura y proceso. Barcelona: Gedisa.

Anexo 1. Listado de canciones incluidas dentro del corpus

\begin{tabular}{|l|l|l|l|}
\hline Autor/intérprete & Año & Canción & Álbum \\
\hline García, Ch. & 1994 & Fax U & La hija de la lágrima \\
\hline Drexler, J. & 2004 & Anda & La edad del cielo \\
\hline García, Ch. & 1998 & Soldado de lata & El aguante \\
\hline Páez, F y Sabina, J. & 1998 & Llueve sobre mojado & Enemigos íntimos \\
\hline Bunbury, E. & 2002 & No se fíe & Flamingos \\
\hline Bosé, M. & 2002 & $\begin{array}{l}\text { No hay un corazón que } \\
\text { valga la pena }\end{array}$ & Lo mejor de Bosé \\
\hline
\end{tabular}


¿DE QUÉ HABLAMOS CUANDO HABLAMOS DE AMOR?

UN ANÁLISIS A LAS METÁFORAS DEL AMOR EN ALGUNAS CANCIONES DE POP ROCK EN ESPAÑOL

\begin{tabular}{|c|c|c|c|}
\hline Los Prisioneros & 1990 & Estrechez de corazón & Corazones \\
\hline Los Rodríguez & 1991 & Mi enfermedad & Buena suerte \\
\hline Calamaro, A. & 1997 & Me arde & Alta suciedad \\
\hline García, Ch. & 2003 & Asesíname & Rock and roll Yo \\
\hline Aterciopelados & 1998 & Maligno & Caribe atómico \\
\hline Aterciopelados & 2000 & Rompecabezas & Gozo poderoso \\
\hline Mateos, M. & 1986 & Romper un corazón & Solos en América \\
\hline Attaque 77 & 2003 & Arrancacorazones & Antihumano \\
\hline Sabina, J. & 1996 & Contigo & Yo, mi, me, contigo \\
\hline $\begin{array}{l}\text { Los Rodríguez \& } \\
\text { Sabina, J. }\end{array}$ & 1995 & $\begin{array}{l}\text { Todavía una canción de } \\
\text { amor }\end{array}$ & $\begin{array}{l}\text { Palabras más, palabras } \\
\text { menos }\end{array}$ \\
\hline Bunbury, E. & 2004 & El rescate & El viaje a ninguna parte \\
\hline Calamaro, A. & 2006 & Miami & El palacio de las flores \\
\hline García, Ch. & 1991 & Tu amor & Tango 4 \\
\hline Café Tacvba & 2007 & Quiero ver & Sino \\
\hline $\begin{array}{l}\text { Los Auténticos } \\
\text { Decadentes }\end{array}$ & 2003 & $\begin{array}{l}\text { A mí no me importa el } \\
\text { dinero }\end{array}$ & Sigue tu camino \\
\hline Café Tacvba & 2003 & Eres & Cuatro caminos \\
\hline Enanitos Verdes & 1988 & No me verás & Carrusel \\
\hline Soda Stereo & 1990 & De música ligera & Canción animal \\
\hline Sabina, J. & 1992 & Amor se llama el juego & Física y química \\
\hline $\begin{array}{l}\text { Calamaro, A. (Mores, } \\
\text { M.) }\end{array}$ & 1999 & Jugar con fuego & Honestidad brutal \\
\hline Calamaro, A. & 1999 & Paloma & Honestidad brutal \\
\hline Calamaro, A. & 1999 & Socio de la soledad & Honestidad brutal \\
\hline Páez, F. & 1994 & $\begin{array}{l}\text { Nadie detiene al amor en un } \\
\text { lugar }\end{array}$ & Circo beat \\
\hline Bunbury, E. & 2002 & Enganchado a ti & Flamingos \\
\hline Amaral & 2005 & Te necesito & La barrera del sonido \\
\hline Estopa & 1999 & Tu calorro & Estopa \\
\hline Serú Girán & 1978 & Eiti Leda & Serú Girán \\
\hline
\end{tabular}


¿DE QUÉ HABLAMOS CUANDO HABLAMOS DE AMOR?

UN ANÁLISIS A LAS METÁFORAS DEL AMOR EN ALGUNAS CANCIONES DE POP ROCK EN ESPAÑOL

\begin{tabular}{|l|l|l|l|}
\hline El Último de la Fila & 1988 & A veces se enciende & $\begin{array}{l}\text { Como la cabeza al } \\
\text { sombrero }\end{array}$ \\
\hline Spinetta, L. A. & 1991 & Seguir viviendo sin tu amor & Pelusón of milk \\
\hline
\end{tabular}

